\title{
The Dominant Design of Disruptive Innovations in the 3rd-Party Online Payment in China
}

\author{
Lu Lu $\mathbb{D}^{1},{ }^{1}$ Yang Zhou $\mathbb{D}^{2}{ }^{2}$ Chenxiao Wang $\mathbb{D}^{1},{ }^{1}$ and Qingpu Zhang $\mathbb{C}^{1}$ \\ ${ }^{1}$ School of Economic and Management, Harbin Institute of Technology, Harbin, 150001 Heilongjiang, China \\ ${ }^{2}$ Business School, University of Shanghai for Science and Technology, Shanghai 200000, China \\ Correspondence should be addressed to Qingpu Zhang; zzqp2000@hit.edu.cn
}

Received 23 April 2021; Revised 31 May 2021; Accepted 11 June 2021; Published 28 June 2021

Academic Editor: Wenqing Wu

Copyright ( $2021 \mathrm{Lu} \mathrm{Lu}$ et al. This is an open access article distributed under the Creative Commons Attribution License, which permits unrestricted use, distribution, and reproduction in any medium, provided the original work is properly cited.

\begin{abstract}
As a disruptive innovation on the traditional payment mode, the 3rd-party online payment has been involved in disruptive innovations featuring contextualized and modernized characteristics, but a theoretical summary is urgently needed for the dominant design of these disruptive innovations. Therefore, an in-depth case study is done with Alipay and PayPal as the subject, and it comes to elaborate four key aspects involved in the dominant design of disruptive innovations of the 3rd-party online payment. Namely, adopt new innovative derivations, create new product attributes, construct new business models, and process subsequent performance improvements. In addition, the factors that differ from the traditional disruptive innovations are also spotted, including two innovative driving forces, two new product features, and four business modes.
\end{abstract}

\section{Introduction}

In recent years, the demand of online payment in China is so vast that domestic and international online payment agencies compete for this "big cake." Interestingly, the world's largest online payment company PayPal Co. does not perform satisfyingly in China. On the contrary, the local inexperienced company Alipay Co. develops prosperously. Its market share has already surpassed the former incumbent China UnionPay in Chinese online payment market. According to the statistics report of Analysys Co., titled "Shares of 3rd-party Payment Platforms in the Online Market Trading in the 1rd Quarter of 2020," by the end of the statistical period, the total online trading deals reached RMB 64.03355 trillion, among which the share of Alipay (belongs to Alipay Co.), Tencent Financial (belongs to Tencent Co.), and ChinaPay (belongs to China UnionPay) occupies $48.44 \%, 33.59 \%$ and 9.75\%, respectively, and the share of PayPal China (belongs to PayPal Co.), however, has dropped to less than $1 \%$ [1].

Alipay Co. was no more than an unnoticeable private company at beginning. Finally, it replaced ChinaPay's incumbent position and obtained the largest share in the market of online payment. From this view, it conforms to the result of disruptive innovation proposed by Christensen, namely, the entrant company firstly focusing on a low-end market or an emerging market, gradually eroding the incumbent company's market share, and ultimately replacing their dominant position [2-7]. Is the development process of Alipay Co. indeed a disruptive innovation?

So far, the theory of disruptive innovation has been verified in many industries, such as hard disk drive industry, iron and steel industry [2], cellular phone industry [6], computer industry, retail industry, service industry, and manufacturing industry [3]. However, the existing researches focused mainly on the substantive products or the face-to-face services. The $\mathrm{R} \& \mathrm{D}$, manufacturing, and marketing processes of these products or services were in a relatively stable environment. There is a lack of research on whether disruptive innovation theory is appropriate for virtual products and services in the emerging context. Meanwhile, the cases and data collected to construct or verify the theory mainly derived from companies in developed areas, e.g., the United States and Europe $[8,9]$. The existing research on successful disruptive innovations does not apply to other companies in the volatile market [10]. To our knowledge, rare research explains why different companies' innovations in China turned into 
different results, just like Alipay Co and PayPal Co. did. It is in need for further theoretical exploration on disruptive innovation issues in Chinese context.

The 3rd-party online payment companies suffer from more challenges in Chinese context. Firstly, technology changes rapidly, which makes the chance for technology innovation easier to fleet [11]. Secondly, information bursts drastically, which makes the concealed market demand easier to be submerged $[12,13]$. Thirdly, trade virtualizes extensively, which facilitates the shift of valuable product attributes [12, 14-16]. Fourthly, Chinese online payment starts relatively late. The public awareness of online payment security is insufficient. The construction of credit system is not complete enough, causing the lack of constraints on the dishonest behaviors in online payment [17]. Fifthly, Chinese government takes regulation on the 3rd-party online payment to some extent. Only these 3rd-party payment companies which obtain the "3rd-party electronic payment license," issued by the central bank, can engage in the 3rd-party payment activities within the territory of China [18].

Chinese context is so special with general disruptive innovation theory or practice hardly explaining some cases in China perfectly. For example, the dilemma of PayPal Co. in China shows us that even the mature development mode that is verified to be successful in other places of the world may not be appropriate for Chinese context. What are the common characteristics of the successful disruptive innovations of the 3rd-party online payment in Chinese context?

Three disruptive innovation products of Alipay Co. were selected as successful cases, and three products of PayPal Co. were selected as control cases. Based on the cases, we found that the successful disruptive innovations of the 3rd-party online payment not only keep to the relative propositions of disruptive innovation theory but also adapt to Chinese context, while unsuccessful ones fail in doing so. These adaptations include the following: (1) adapt to the corresponding Chinese context when identifying the innovation derivations, (2) create new product attributes that highlight security and quickness, (3) construct new business models to fit the disruptive innovation products, and (4) process subsequent performance improvement. The empirical analysis of these assumptions constitutes the main content of this paper.

\section{Theoretical Background}

2.1. Corresponding Points of Disruptive Innovation Theory. According to the disruptive innovation theory, innovations are divided into two classifications: disruptive and sustaining $[2,3]$. The differences between these two kinds of innovations mainly concentrate on two aspects, technological change and customer segment, which is shown in Table 1.

Disruptive innovation derives from the incumbent's failure in dealing with the change of technology and market demand, as well as the entrant's venture on the derivations $[2,3]$. According to the resource dependency theory, incumbent companies would always tend to allocate the limited resources to the customer segment that could bring them more profits [19]. Thus, they concentrate on the vaster and more profitable existing mainstream market and neglect the low-end market or new emerging market that seems less profitable at present. The more resources flow into mainstream market; the harder incumbent makes a shift to other markets. The entrant accurately utilizes incumbent's dilemma and provides products to the low-end market or emerging market. Some attributes of the product may be inferior to that of the mainstream products, but it has some attributes that low-end or emerging customers appreciate, such as cheapness, simplicity, and convenience. The mainstream customers generally do not want to use the disruptive products at beginning. So incumbents conclude that it is not a rational decision to allocate resources to the low-end market or emerging market and neglect the opportunity to invest in disruptive innovation. The entrant who implements disruptive innovations steadily improve in product performance until it meets the standards of performance demanded by the mainstream market. At that point, the incumbents' reaction to disruptive innovation is late and ineffective. The entrant finally displaces the dominant incumbents in the mainstream market.

In sum, sustaining innovations strengthen the dominance of the incumbent companies, whereas disruptive innovations enable entrant companies to replace incumbents over time. The latter, which is considered more significantly change the whole industry $[2,20]$, attracts more and more attention of researchers and practitioners [21].

2.2. Contextualization of Disruptive Innovation Theory. Since Christensen firstly put forward the conception of disruptive innovation in 1997, disruptive innovation theory only has a more than 20-year-long development history. Christensen stated that there are two stages in the construction and development process of disruptive innovation theory, descriptive stage, and normative stage [22]. Each stage consists of three steps. Currently, researches on disruptive innovation mainly focused on the three steps in the descriptive stage-observation, categorization, and association. On the one hand, the constructs, frameworks, and models of the theory were constructed in some studies $[2,3,5,6,8,23]$. On the other hand, anomalies are found and the constructs and hypotheses are refined by other studies [9, 24, 25].

However, those prior studies still remained in the descriptive stage. The development of theory needs to transit from descriptive stage to normative stage. The normative theory has more predictive power than the descriptive theory, for the reason that researchers building normative theory categorize different situations or circumstances in which managers might find themselves [22], and the circumstance-contingent predictive power of normative theory enables managers to know what they ought to do given their circumstance. Therefore, the further development of disruptive innovation theory tends to be contextualization [22].

This point of view is supported by the related theory in the research field of organizational management. Lawrence and Lorsch's contingency theory [26] stated that the best way to organize a company depended on the circumstances in which the company was operating. Context assimilation impedes us to understand what happens in the context different from the mainstream paradigm $[27,28]$. Contextualize 
TABLE 1: Differences between disruptive innovation and sustaining innovation.

\begin{tabular}{lll}
\hline & Disruptive innovation & Sustaining innovation \\
\hline Technological change & $\begin{array}{l}\text { (i) "Degeneration" along the existing trajectories, } \\
\text { simplification of the existing technology, solution } \\
\text { of the technology overload } \\
\text { (ii) Escape from the existing technological trajectories, } \\
\text { entrance into a new trajectory }\end{array}$ & $\begin{array}{c}\text { (i) Incremental or radical improvement along } \\
\text { the existing trajectories }\end{array}$ \\
\hline Customer segment & $\begin{array}{l}\text { (i) Low-end customers for whom mainstream technology } \\
\text { was excess } \\
\text { (ii) Noncustomers }\end{array}$ & $\begin{array}{l}\text { (i) Mainstream customers who have not been } \\
\text { satisfied by the antecedent technology }\end{array}$
\end{tabular}

theory is helpful to identify the boundary conditions of a theory or to adjust the predictive power of a theory in the new context [29]. In addition, some researches on organizational behavior pointed that there are many special context factors in Chinese context which are very useful for understanding the Chinese organizational behavior [30].

Many local and international companies are waiting for the time to disrupt China's 3rd-part online payment market as this market is such profitable and attractive. However, the Chinese context is distinct. It is of great significance to study on the disruptive innovation of the 3rd-party online payment in Chinese context.

\subsection{Dominant Design of Disruptive Innovation Theory.} Utterback and Abernathy [31] first introduced the concept of Dominant design in 1975. If a dominant design wins the position on the market, then, the competitors and innovators must adhere to this dominant design if they hope to capture market share [32]. A dominant design can be a new technology, a new product or a set of key factors of different technological innovations from existing products. Dominant design may not be better than other designs, but it still can have dominating positions in the market. This may be due to network effects, technological superiority, appropriate business model, or strategic manipulation by business managers.

Before a dominant design achieves its status, companies will continuously explore its development modes. As a result, economy of scale cannot be realized during this period. After a dominant design comes out, earlier developing firms, with advantages in market shares, will soon resort to economy of scale, thus increasing the barriers to entry to and flow of the industry. That is the reason why earlier developing firms have advantages over latecomer firms [8]. As a dominant design is acknowledged only when it procures over $50 \%$ of the market sharer, it is often recognized after successfully achieving its dominance [20].

Disruptive innovation is a process of breaking the original market pattern and reconstruction of a new market structure [11]. However, before the new market is established, there will be a time when numerous disruptive innovative designs coexist. When brought to the market test, those inappropriate designs will be eliminated and a dominant design will come out. Then, the industry will continue its development under the guidance of the new dominant design [33]. The 3rd-party online payment in China is just experiencing a disruptive innovation process as above. Therefore, based on the existing theoretical framework of disruptive innova- tion, this paper explores the dominant design of disruptive innovation in the 3rd-party online payment in China.

\section{Method and Data}

3.1. Research Design. Contextualization, as well as idealization, is the practical strategy of inductive reasoning, providing the logical thread when the theoretical conclusions are drawn from empirical data [34], from particulars to generalizations and from grounds to claims [35]. In contrast with idealization that is abstracted and idealized, contextualization is aimed at providing maximal access to the example and contextual detail to establish a sense of empirical authenticity [36]. Ketokivi and Mantere [34] suggested one kind of contextualization, theoretical contextualization, through which relevant propositions would be established with respect to a particular theory [34]. Namely, this method processes both explanation of the links between the empirical data and the concerns of a theory and inference based on the empirical data, which is quite applicable for our study. Meanwhile, in respect to the fact that there is few research on disruptive innovation of the 3rd-party online payment in China, this inductive method is suitable [37].

Following the process of theoretical contextualization, the specific phenomenon is analyzed based on the existing theory at first. Then, the new propositions are inducted and verified. Digging into the data of Alipay Co. and PayPal Co., we finally choose to focus on identifying the common characteristics in successful disruptive innovations of the 3rd-party online payment in Chinese context. We select a series of cases, each of which is used to confirm or deny the conclusion of any other case, which allows for theoretical replication in a multicase study [37]. The multicase study is more complex than the single-case study; therefore, it provides a more reliable result $[11,33]$.

3.2. Data Collection. Secondary data of Alipay Co. and PayPal Co. is collected, including related literatures, news on Internet, public performance reports, the statistical analysis reports from EnfoDesk Co., executives' blogs, and public lecture materials.

Secondary data is more suitable for this study for the reasons as follows. Firstly, the macrolevel research of management mainly relies on the secondary data and there are too numerous examples that use secondary data in organizational theory research to mention one by one [38]. The issue of disruptive innovation refers to the organizational level, 
rather than the individual level. Secondly, secondary data allows for time span [38]. It needs a certain amount of time waiting for the reflection before judging out whether a potential disruptive innovation is successful or not. Some innovations may fail, while others may progress to spark an era of disruption when they reach a "good enough" point, through a relatively longer time horizon of experimentation and adaptation [39]. Disruptive innovation is a problem with time span on which secondary data has an obvious advantage. Thirdly, the disruptive innovation of the 3rd-party online payment is in a high-velocity environment. Limited by individual ability, the individuals can hardly form a clear and accurate understanding of the phenomena in this kind of environment [11], so that the first-hand data collected only by the method of questionnaires or interviews may be subjective to some extent. However, in the solution of this problem, secondary data is more objective.

We set up the research team of 4 experts who are engaged in disruptive innovation theory or practical research to analyze all of innovation activities of the two companies since they were established to now. According to the method of theoretical sampling, the successful cases are selected only if a company's market share turns up a significant increase after the advent of innovation. Finally, three disruptive innovation products of Alipay Co. are selected as the successful disruptive innovation cases. They are Alipay, Yu'ebao, and mobile wallet. And three products of PayPal Co. are selected as control cases. They are PayPal, PayPal China, and PayPal money market fund (PayPal MMF).

Different from confirmatory researches, there is a lack of normative framework for induction research [34, 40].Thus, we adopt the following method: from the numerous data, the "whole story" according to the time sequence of each case is extracted. Each case begins with the advent of the disruptive product and includes all events related to it mentioned in the data. Common characteristics are concluded through comparison within the successful cases. And the differences between successful cases and control cases are also concluded through comparison between two case groups. The variables that occur in each case are sorted out, and the tentative relationships are concluded. Then, we return to each case to verify whether these findings are valid. After repeated comparison and verification between data and hypotheses, a comparison between our findings and existing literatures is conducted, through which the "commons" and "exceptions" of disruptive innovation of the 3rd-party online payment in Chinese context are highlighted.

\section{The Dominant Design of Disruptive Innovations}

Existing findings declared that some disruptive innovations are facilitated by technology breakthrough, the occurred conditions of which are similar with the technology-oriented breakthrough innovation $[2,3,23]$. This kind of disruptive innovation usually occurs in the high-end market that is technology-oriented $[5,6,23]$. However, some other disruptive innovations are facilitated by the special target of customer segment. When there are customers who feel the products in mainstream market providing them excess functions and charging them for these functions they never use or there are customers who want to pay for other functions that the existing products do not provide, companies target at these customers who consist of the special customer segment that is called "the niche market" $[41,42]$. In the niche market, disruptive innovation gradually erodes to the mainstream market and finally disrupts it. This kind of disruptive innovation usually occurs in the low-end market or new market $[2,3]$. In most cases, the occurred condition of disruptive innovation is mixed, based on both technology breakthrough and accurate target of the niche market.

The consistent conclusion of disruptive innovation has been reached among researches under the background of traditional industries: the disruptive innovation initially underperforms the mainstream one but is "typically cheaper, simpler, smaller, and frequently more convenient" $[2,5,7]$. Perceived safety is an important factor for consumers who purchase online service products [43]. Zhang et al. [44] analysis the disruptive innovations for microcredit mentioning efficiency and safety-the two new attributes of products. Based on a flexible business model, these new products have taken the lead in the market [44].

Disruptive innovation can be caused by a new technology or a solution and can be eventually accompanied by an alteration of the existing business model $[45,46]$. Corporate decision-making, action, and value network will impact the driving force and effect of disruptive innovations [47]. It is only a one-side view to think that it means the end of disruptive innovation once the innovation is commercialized. Disruptive innovation is a process [22]. Every type of disruptive innovation put forward requires different business ecosystems to be practicable and disruptive [47]. Whether the suitable business model can be constructed at the subsequent stage of this process is also the key to the success of disruptive innovation. Disruptive innovations represent a process, and the products of disruptive innovations in the early period are less impressive than mainstream products. But constant improvements can be made to enable quick iterations of product attributes and business models for gradually taking the lead [2, 3].

Therefore, we propose the following propositions:

Proposition 1. The successful disruptive innovations of the 3 rd-party online payment are able to identify and utilize the innovation derivations in Chinese context.

Proposition 2. In China, the successful disruptive innovations of the 3rd-party online payment follow the new special product attributes.

Proposition 3. In China, the successful disruptive innovations of the 3rd-party online payment obtain sustaining profitability through constructing the suitable business model.

Proposition 4. In China, the successful disruptive innovation of the 3rd-party online payment obtains sustaining profit by the subsequent continuous improvement. 


\section{Background Information of Each Case}

5.1. Alipay. Alipay is a product of Alipay Co. launched on Oct. 18, 2003. At beginning, Alipay is only a payment mode for the e-commerce web sites, http://Taobao.com/ and http://Tmall.com/, playing a guarantee role between the seller and buyer. When the trade agreement is achieved, the buyer pays the bill using his Alipay account. However, in fact, the money does not directly go into the seller's account but is held by Alipay Co. momentarily. When the buyer receives the product, the buyer clicks the confirm button to transfer money from Alipay Co. to the seller's Alipay account provided that he is satisfied with the product. Otherwise, the buyer returns the product to the seller and asks for drawback the money from Alipay Co.

Before the advent of Alipay, the main payment modes in e-commerce are traditional post office remittance, pay on delivery, and online banking. These modes either make logistics lag behind capital or make capital lag behind logistics, which brings much more risks on either of the two parties. The 3rd-party online payment acts as a guarantor role in ecommerce, bearing the trade risks. It is of great contribution to the rapid development of e-commerce.

Alipay introduces several security measures to protect users' Alipay accounts such as digital certificate and authentication messages on cellphone. Meanwhile, it puts forward the slogan "you dare to use, I dare to compensate" to commitment that if the user happens to be stolen owing to the security problem, Alipay Co. would pay for the full loss. On the other hand, it no longer just stays to http://Taobao .com/ or http://Tmall.com/, but expanses its boundary. First, it cooperates with many other e-commerce sites, such as http://JD.com/ and http://DangDang.com/. Second, it provides payment service for public utilities, such as water electricity payment and ticket payment. Third, it provides cross-border payment service and bulk payment service.

5.2. Yu'ebao. Yu'ebao is a cooperation product of Alipay Co. and Tianhong Fund Co. launched on Jun. 17, 2013. The money in Yu'ebao accounts equals to buy the money market fund (MMF) of Tianhong Fund Co., and the profit is given to the users. However, different from traditional MMF, Yu'ebao does not charge any fees and gives daily profit. The user can use the money in Yu'ebao account to pay the bill directly or withdraw them to bank account. With Yu'ebao, there are no longer restrictions of the minimum purchase threshold and the fixed redemption date. More and more people are interested in Yu'ebao because of its profitability and flexibility. According to Souhu Net report, until the end of 2017, the total capital in Yu'ebao accounts approximated RMB 1.5 trillion and the user number had exceeded 600 million [48].

Yu'ebao account is bounded to Alipay account, which allows users to transfer the money between the two accounts freely. Alipay has a large number of users who are easy to accept Yu'ebao, which accelerates the extension of Yu'ebao. And the finance function of Yu'ebao also strengthens the user viscosity of Alipay and attracts more users to use Alipay. The two products promote each other and jointly enhance the overall competitiveness of Alipay Co.
5.3. Mobile Wallet. Mobile wallet is a mobile payment product of Alipay Co. Mobile payment refers to the new payment mode using mobile terminal to realize "paying online and experiencing offline $(\mathrm{O} 2 \mathrm{O})$." Chinese virgin mobile payment market is so vast that attracts lots of companies competing for it. Many other companies launched their own mobile payment product, too: Tencent Holdings' TenPay wallet, Suning's Yifubao wallet, Baidu's Baidu wallet, etc. This intensified competition was called "the fight for the entrance of mobile payment" by Ma Yun the founder of Alipay Co.

In order to survive in this fight, Alipay Co. took several measures to improve the attributes of mobile wallet and implemented a new marketing model to commercialize the mobile wallet. Firstly, new functions such as "acoustic payment," "sweep-code payment," and "AA payment" were added to mobile wallet. Secondly, Alipay Co. decisively adopted a new marketing model to strengthen the fight for mobile payment market. It cooperated with the mobile APP Kuaidi Taxi and successively invested more than RMB 1 billion, giving subsidies to the tax drivers and passengers who use this APP and mobile wallet. Thanks to this marketing model, users knew and adopted mobile wallet in the shortest time. One professional visitor appraised it as "a disruptive marketing that is more powerful than any advertising." In just 3 months during the end of 2013 to the beginning of 2014, the user number of mobile wallet exceeds 170 million.

5.4. PayPal. PayPal is a 3rd-party online payment product of PayPal Co. It was launched in 1998 and was purchased by the famous American e-commerce company ebay Co. after which PayPal became the main payment mode on http:// ebay.com/. Gradually, many other e-commerce companies cooperated with PayPal Co. one after another. As PayPal provides the payment transaction among 6 kinds of currency (USD, CAD, EUR, GBP, JPY, and AUD), it is widely used in international transactions. PayPal is commercialized by e-mail, which leads the user number becoming larger and larger, just like snowball rolling. PayPal quickly occupied the largest share of international online payment market thanks to this kind of marketing called "email virus marketing style."

However, PayPal is based on credit payment system directly. The user can only use his own credit card to transfer money to his PayPal account. So the people who do not have a credit card are unable to register PayPal accounts. On the other hand, when using PayPal in the e-commerce transactions, the buyer transfers the money directly into the seller's PayPal account. The money is received in real time. Theoretically, the seller can bring away the money without delivering the product to the buyer. So there still exists some security risk in PayPal.

When the user pays by PayPal, it does not charge any fee. But when the user receipts the money, it charges some handling fee, which makes up the main incomes of PayPal Co. The handling fee is the base fee (generally around 3\%) plus 0.3 dollars. The maximum is limited within 5 dollars.

5.5. PayPal China. PayPal China is the product that PayPal Co. specially designed for Chinese users. It oriented to the 
transactions by CNY, transferring CNY between PayPal China accounts and bank accounts. PayPal Co. not only adopted a free policy for the payers in China but also made an exception to accept transactions by CNY only, unlike in other places that generally adopted the multicurrency transaction. However, PayPal China still charge receivers a fee.

Since Sep. 1, 2010, the central bank, People's Bank of China, introduced "Non-financial payment services management method" to strengthen the management of nonfinancial institutions engaged in payment service. It stipulated that only the 3rd-party institutions that obtained the payment business license were allowed to engage in $\mathrm{CNY}$ payment service within Chinese territory. Unfortunately, PayPal China has not acquired the payment business license so far. Since then, PayPal China's shares in China's 3rd-party payment market decreased sharply. PayPal China had to find another way out. Finally, it turned to the international crossborder payment service although it is less attractive.

5.6. PayPal MMF. PayPal MMF is an open-end money market fund based on users' PayPal account balances, set up by PayPal Co. in United States in 1999. This fund mainly invests in the high-quality and short-term money market instruments denominated in dollars. The operation mode and the dividend distribution principle of PayPal MMF were similar with those of Yu'ebao, which attracted users to keep more money in their accounts. During 2005 to 2007, PayPal MMF scrambled a considerable portion of deposit money from the banks by virtue of its high customer profit, which incurs the discontent of banks. Under the pressure of the banks, the U.S. government started to implement the zero interest rate policy.

When the zero interest rate policy was unveiled in 2008, the short-term investment return rate of funds fell to $0.25 \%$ from $0.75 \%$. The performance of all monetary funds including PayPal MMF is very low. Just before PayPal MMF closing, customers could only obtain a profit at the rate of $0.04 \%$ after deducting any fees. The scale of PayPal MMF shrank since it lost its profit advantage. According to the financial report of PayPal Co., before announcing the closure of PayPal MMF, PayPal Co. had actually already subsidized the fund for 2 years in order to maintain positive customer profit. The MMF became a burden that was getting too heavy for PayPal Co. to bear. In June 2011, PayPal Co. eventually chose to abandon PayPal MMF.

\section{Case Analysis: Alipay and PayPal}

Alipay, Yu'ebao, mobile wallet, PayPal, PayPal China, and PayPal MMF are all the disruptive explorations of the 3rdparty online payment. However, their performances in China are quite different. The former three perform actively, while the latter three perform unsatisfactorily in China. Summing up and comparing these cases, we draw some conclusions on common characteristics of successful disruptive innovations in Chinese online payment context. Here, we comprehensively summarized the specific hypotheses for each proposition.
6.1. New Innovative Driving Forces. The successful disruptive innovations of the 3rd-party online payment are able to identify and utilize the innovation derivations in Chinese context. Our data also confirmed these views. Firstly, in Chinese context, successful disruptive innovations of 3rd-party online payment are able to accurately and timely identify innovation derivations facilitated by technology change. The disruptiveness of Alipay reflects in that it establishes and develops along the online payment development trajectory. This process is shown from $T_{0}$ to $P_{a}$ in Figure 1. The disruptiveness of Yu'ebao reflects in that it jumps from the online payment trajectory to online finance trajectory, which is shown from $P_{a}$ to $P_{a}{ }^{\prime}$. The disruptiveness of mobile wallet reflects in that it jumps from the online payment trajectory to mobile payment trajectory, which is shown from $P_{b}$ to $P_{b}{ }^{\prime}$. The customer number of Alipay Co. increases steadily thanks to these three disruptive innovation products, which conforms to the viewpoint of Sun et al. that disruptive innovation is able to break the $S$ curve of innovation diffusion proposed by Rogers [49].

Secondly, successful disruptive innovations of the 3rdparty online payment are able to find out the incumbents whom they are going to disrupt and the niche markets which they are going to derive from. The incumbents and niche markets of each successful cases in our study are summed up as shown in Table 2. Moreover, the context factors facilitating these disruptive innovation derivations are also shown in Table 2.

In addition, we have some new findings. In Chinese context, disruptive innovation derivations of 3rd-party online payment also come from competitive basis change and government regulation.

There are three reasons causing the competitive basis change in Chinese online payment context. First, information is more and more symmetrical, allowing customer to access to all kinds of payment modes. When the number of available alternative payment modes that can also meet customer demand increases, customers' choice criterion transfers from the basic payment function to other product attributes. Second, the Internet security problems cannot be ignored. Since the advent of online payment, it is nothing new to read the news about hackers stealing customers' electronic accounts through Internet, which makes customers take security into consideration when choosing payment modes. Third, in China, due to the historical reasons of market development, the credit management system is imperfect. There is a lack of relevant law and policy constraints to regulate the dishonest activities in online trading. Customers feel insecure about the present payment modes and deeply demand for the new payment product with the "guarantee" attribute. Therefore, we come to the following hypothesis:

H1.1. The successful disruptive innovations of the 3rdparty online payment are able to identify and utilize the competitive basis change in Chinese context.

This finding is somewhat different from the perspective of Christensen on the relationship between disruptive innovation and competitive basis. Christensen stated that it is disruptive innovation that changes the criterion of customers' choice [2]; in other words, disruptive innovation facilitates 


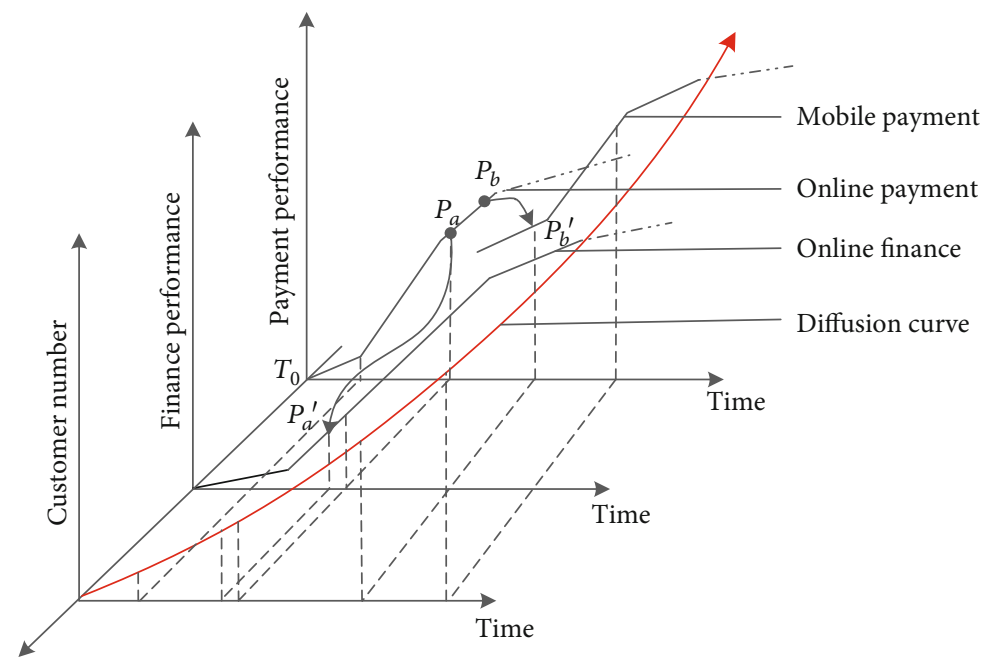

FIgURE 1: Technology change in each successful case.

TABLE 2: Related details of each successful case.

\begin{tabular}{|c|c|c|c|}
\hline & Alipay & Yu'ebao & Mobile wallet \\
\hline Incumbent & $\begin{array}{l}\text { (i) Online bank payment } \\
\text { (ii) Pay on delivery } \\
\text { (iii) Post office remittance } \\
\text { (iv) Bank transfer } \\
\text { (v) Installment payment }\end{array}$ & $\begin{array}{l}\text { (i) Financial products } \\
\text { (ii) Fixed deposit } \\
\text { (iii) Current deposit }\end{array}$ & (i) Online payment \\
\hline Niche market & $\begin{array}{l}\text { (i) The buyer who is worried that he pays } \\
\text { the bill but cannot receive the product } \\
\text { (ii) The seller who is worried that he sends } \\
\text { the product but cannot receive the } \\
\text { money } \\
\text { (iii) The customer who is unsatisfied with } \\
\text { problems of existing payment ways, } \\
\text { e.g., security \& inconvenience }\end{array}$ & $\begin{array}{l}\text { (i) The customer who is unable to meet the } \\
\text { constraints, e.g., minimum purchase } \\
\text { amount \& redemption period of financial } \\
\text { products } \\
\text { (ii) The customer who is unsatisfied with } \\
\text { mobility of fixed deposit } \\
\text { (iii) The customer who is unsatisfied with } \\
\text { low returns of current deposit }\end{array}$ & $\begin{array}{l}\text { (i) The new customer who would like } \\
\text { to use mobile wallet } \\
\text { (ii) The customer who is unsatisfied } \\
\text { with inconvenience of online } \\
\text { payment }\end{array}$ \\
\hline
\end{tabular}

(i) Online payment technology
(ii) Drastic information burst
(iii) Extensive trade virtualization
(iv) Underperforming credit management
context factem
(v) Specific government regulation

(i) Drastic information burst

(ii) Extensive trade virtualization

(iii) Specific government regulation (i) Mobile payment technology

(ii) Drastic information burst

(iii) Extensive trade virtualization the new competitive basis. However, our finding suggests that it is the competitive basis that could change on its own initiative and further facilitate disruptive innovation. The main reason why our finding is different from the existing ones is that the 3rd-party online payment we study on is in the emerging technology environment. Many new product attributes spring up with the emerging technology and become new competitive basis of product suppliers. Thus, suppliers are engaged in disruptive innovation based on the new competitive basis. For example, Internet security is a new product attribute of payment born with emerging online payment technology. These new attributes facilitate Alipay Co. to research and develop the disruptive product Alipay.

On the other hand, from the comparison of PayPal Co. and Alipay Co., we find that PayPal Co. (established in 1997) was established earlier than Alipay Co. (established in 2003). So, the online payment technology is no longer dis- ruptive when Alipay Co. established. Why Alipay also show vivid disruptiveness? That is because of region segmentation owing to domestic regulation. Region segmentation, just like the high entry barrier set by the government, impedes companies to enter in without permit [50]. Chinese government has always been strictly supervising the financial market, so as to maintain the normal order of financial market and promote the construction of financial market system. People's Bank of China has launched the "Regulations for the Payment Services of Non-financial Institutions" on September 1,2010 , which stipulates that only the third-party payment institutions attaining business licenses can engage in RMB payment business in China. Therefore, many successful international 3rd-party online payment companies, such as PayPal, are unable to enter the Chinese market for the lack of this license, which greatly alleviates the fierce competition pressure in China's 3rd-party online payment market, 
providing opportunities for local companies like Alipay to make disruptive innovations in China. This also explains why PayPal China was launched into the Chinese market, but its influence is far less than Alipay. Because in Chinese segment market Alipay Co. is the first to innovate in 3rdparty online payment, while PayPal Co. is just an entrant no long having the absolute advantage. In the meantime, since the 3rd-party online payment market in China is relatively independent from the international 3rd-party online payment market, innovatively introducing 3rd-party online payment technology into Chinese market also can effectively drive the disruptive innovation. Therefore, we put forward the following hypothesis:

H1.2. The successful disruptive innovations of the 3rdparty online payment are able to utilize the region segmentation in Chinese context.

Disruptive innovation is a relative phenomenon [22], which emphasizes the same innovation can be competency enhancing relative to one company and competency destroying relative to another. Our finding further develops this point of view, stating that the nondisruptive innovation in one market segmentation can still be disruptive in other untapped market segmentation caused by government regulation. It has a similar conclusion with the regulation theory. Regulation theory suggests that regulation shapes the competitive situation [9]. The competitiveness of online service innovation changes due to three reasons: basic competition, environment of competition, and competing strategy [43]. Therefore, the special competitive situation under different regulation in different areas offers motivations and abilities for entrants to conduct disruptive innovation.

6.2. New Product Attributes. Based on the analysis of Alipay, Yu'ebao, and mobile wallet, we find that the successful disruptive innovations of 3rd-party online payment all have some new product attributes in Chinese context. The new product attributes of the three successful disruptive innovation cases and the corresponding proof are summarized in Table 3.

As the summary of disruptive product attributes shown in Table 3, we find out two new attributes that Christensen did not mention: security and quickness.

The first is security. The products in online payment are the virtual currency. On the one hand, virtual trade involves credit problems. If there are no effective laws or institutional constraints to restraint the dishonest behaviors, people may choose not to conduct the virtual transaction. It also explains why PayPal Co. is prosperous in developed countries where the credit card payment system is relatively more perfect than in China. The credit system is not perfect enough at present, which makes it hard for the 3rd-party online payment companies to conduct innovations following the development mode of PayPal Co. On the other hand, virtual trading relies on the security of Internet. The thefts and frauds in online payment took place frequently in China or other countries. In such situation, it was in great need of a payment product that can guarantee the security. Thus, we put forward the following hypothesis:
H2.1. It highlights security among the competitive basis of the 3rd-party online payment disruptive innovation in Chinese context.

The second is quickness. In addition to the payment function of online payment product, people pay more and more attention to its quickness. The disruptiveness of Alipay reflects in that it makes the payment quicker than the laborious payment modes such as bank transfer. The disruptiveness of mobile wallet reflects in that it makes the payment further quicker than the online payment. The quickness of the 3rd-party online payment has become an important product attribute nowadays. Therefore, we put forward the following hypothesis:

$\mathrm{H} 2.2$. It highlights quickness among the competitive basis of the 3rd-party online payment disruptive innovation in Chinese context.

6.3. Suitable Business Models. Based on the analysis of Alipay and PayPal, we find that the business models including the profit mode, the operation mode, the marketing mode, and the incentive mode are very special in our cases. The details are summarized in Table 4.

Alipay, Yu'ebao, and mobile wallet all charge normal users for free, while PayPal and PayPal China do not. As "free" mode benefits users more, Alipay Co. wins more users than PayPal Co. It means that Alipay Co. dose not regard the transaction fee as a profit source. But it would like to profit from advertisement, data analysis service, and other ways after its market share is big enough. That is what the president of Alipay Co. Mr. MA Yun said "Make the market share big first. Everything will be well if the market share is big." We put forward the following hypothesis:

H3.1. The "free" mode gives more profit to customers in the subsequent stage of disruptive innovation.

Alipay Co. is the subsidiary company of Alibaba Co, the biggest $\mathrm{B} 2 \mathrm{~B}$ and $\mathrm{B} 2 \mathrm{C}$ e-commence company in China. At beginning, the main purpose of Alipay Co. is to provide the payment service for the trades on Alibaba Co.'s ecommence sites. Alipay Co. obtains a strong customer base since it integrates to e-commence sites. Gradually, Alipay Co. wins a monopoly on payments of these sites.

Yu'ebao and mobile wallet all integrates to Alipay. In the process of their diffusion, Alipay provides them with a huge customer base, which makes them to be known and adopted by a large number of customers in a very short time. On the other side, when the performances of Yu'ebao and mobile wallet are improved, their influence rises. Then, they will in turn attract new customers who are in favor of the financial function and mobile payment function of Yu'ebao and mobile wallet to use Alipay. Finally, the user number of all the three products will rise. What is more important, Yu'ebao and mobile wallet increase the user viscosity of Alipay, which greatly enhances Alipay Co.'s competitiveness.

Comparing with Yu'ebao, PayPal MMF fails in constructing a suited business model, which facilitates its final failure. Yu'ebao inherits all payment functions of Alipay and gives customers a profit higher than the interest of current deposit interest. It allows customers to both pay and manage their money, which meet their composite demand, 
TABLE 3: The abstract of disruptive products' attributes.

\begin{tabular}{|c|c|c|}
\hline & Alipay & Mobile wallet \\
\hline Simplicity & $\begin{array}{l}\text { Online bank payment } \\
\text { (i) Redundant operations between banks } \\
\text { Alipay } \\
\text { (i) Provide a unified platform } \\
\text { (ii) Reduce operations of the banks \& users } \\
\text { (iii) Transfer money freely, Alipay-to- } \\
\text { Alipay, bank-to Alipay, \& Alipay-to- } \\
\text { bank }\end{array}$ & $\begin{array}{l}\text { Online payment } \\
\text { (i) Pay on a computer in a certain place } \\
\text { (ii) Enter redundant ID \& password } \\
\text { information } \\
\text { Mobile wallet } \\
\text { (i) A mobile phone bound to Alipay } \\
\text { (ii) Enter a 6-letter password } \\
\text { (iii) Pay through QR code \& sound wave \& } \\
\text { phone number }\end{array}$ \\
\hline
\end{tabular}

Yu'ebao

Traditional financial products

(i) Put collected money into profitable investment

(ii) Allot the profit to customers proportionally, \& earn the profit gap

(iii) Set minimum purchase threshold

(iv) Neglect the scattered customers

(v) Bring companies few benefit increase management burden Yu'ebao

(i) Target at the scattered customers

(ii) Based on the low-cost internet platform

(iii) Conceal minimum purchase threshold

\section{Post office remittance \& bank transfer \\ (i) Specific place \& specific time Alipay \\ (i) A device connected to Internet \\ (ii) Pay anywhere and anytime}

Traditional payment \& online payment

(i) Specific place or at least an internet device Mobile wallet

(i) A connected mobile phone

(ii) Pay anywhere and anyplace.

Money in Yu'ebao account can use to pay

the bill and also can earn profit.

(i) Payment function as it integrating to Alipay

(ii) Financial function giving users some profit.

Yu'ebao gives users more profit

(i) Collect scattered money, \& turn into a large funds cumulatively

UnionPay

(i) Charge a fee in interbank or across region payment

Similar to Alipay

(ii) Negotiate with bank on the interest rates \& obtaining a higher interest rate

(i) Charge normal users no fee

(iii) Allot profits to users proportionally

(iv) Profit equivalent to long-term wholesale deposits

Traditional financial products

(i) Fixed redemption period

Traditional payment \& online payment

(ii) Response lag to depression of financial market Yu'ebao

Alipay is more secure than traditional

(i) Passwords are easily lost or stolen payment

(ii) It is easy to make mistakes in operation (transfer to the wrong

Security (i) "3rd-party guarantor"

(ii) Put forward the slogan of "you dare to buy I dare to compensate" account) Mobile wallet

(i) Specific transaction voucher

(ii) Dechange

(iii) Guarantee function

(i) Withdraw immediately, reducing the risk

(ii) The scattered users' small account

(iii) Random redemption behavior

(iv) Low risk of mass redemption \& capital shortage

Traditional financial products

Traditional payment \& online payment

(i) Use complicated ID and password

(i) Redemption period is at least 1 month input

Post office remittance, bank transfer, etc.

Quickness

(i) Receive in several days or several hours Alipay

(i) Receive \& pay immediately (ii) On the account in a matter of hours or days Mobile wallet

(i) On the account instantly (ii) Fixed deposit

(iii) Redemption period is at least 1 year Yu'ebao

(i) Small amount: 2 hours

(ii) Large amount withdraw: 1 work day while PayPal MMF is relatively independent and has no function other than a fund. In addition, Yu'ebao also gives customers a perfect experience. The profit is calculated by compound rate every day. Customers can see the increase of money in their Yu'ebao account. It is indeed a mental stimulation giving rise to psychological satisfaction for customers, especially for the ones who are sensitive to financial profit. Therefore, we put forward the following hypothesis:

H3.2. The "integrating" mode gives more profit to customers in the subsequent stage of disruptive innovation.

The superiority of the "integrating" mode in disruptive innovation diffusion is also verified in some other industries. Sultan researched on the case of Microsoft Co. [24]. He stated, as is customary with Microsoft office, many of its products tend to integrate well with each other. The newest product SharePoint is not an exception to integrate to its famous product Microsoft office. By doing so, Microsoft Co. does not only popularize its new product quickly but also gives customers more conveniences by allowing them to save Office Word file to SharePoint.

Mobile wallet is Alipay Co.'s important product to contend in mobile payment market. However, this "blue ocean" also attracts the attention of other companies. Ma Yun called this battle "the layout war of mobile payment." In China, the most important competitors of mobile wallet are TenPay wallet. The two competitors both have strong parent 
TABle 4: Comparison of each case's business models.

\begin{tabular}{|c|c|c|c|c|}
\hline & Fee (unit: dollar) & Integrating & Marketing & Incentive \\
\hline Alipay & Free & $\begin{array}{c}\text { Integrating to http://taobao.com/ } \\
\text { \& http://tmall.com/ }\end{array}$ & $\begin{array}{l}\text { Marketing through http://taobao.com/ } \\
\text { Taking advantage of the powerful user } \\
\text { base of http://taobao.com/ }\end{array}$ & $\begin{array}{l}\text { Credit incentive mode } \\
\text { Charity incentive mode }\end{array}$ \\
\hline Yu'ebao & $\begin{array}{c}\text { Free } \\
\text { Giving a profit }\end{array}$ & Integrating to Alipay & $\begin{array}{l}\text { Marketing through Alipay } \\
\text { Giving users more profit } \\
\text { Engaging on the margins of policy } \\
\text { Speculating through media }\end{array}$ & $\begin{array}{l}\text { Member points reward } \\
\text { Consumption bonus } \\
\text { rewards }\end{array}$ \\
\hline Mobile wallet & Free & Integrating to Alipay & Marketing through a taxi app & $\begin{array}{l}\text { Consumption rewards } \\
\text { Charity incentive mode }\end{array}$ \\
\hline PayPal & $\begin{array}{c}\text { Withdraw: free } \\
\text { Payment: free } \\
\text { Receipt: }(1.9 \% \sim 2.9 \%) * \\
\text { sum }+0.3\end{array}$ & Integrating to http://ebay.com/ & Email virus marketing style & Discount coupon \\
\hline PayPal MMF & $\begin{array}{c}\text { Free } \\
\text { Giving a profit }\end{array}$ & Integrating to PayPal & - & - \\
\hline PayPal China & $\begin{array}{c}\text { Withdraw: } 35 \\
\text { Payment: free } \\
\text { Receipt: }(2.9 \% \sim 3.9 \%) * \\
\text { sum }+0.3\end{array}$ & - & Marketing focus on cross-border payment & Discount coupon \\
\hline
\end{tabular}

TABLE 5: The continuous improvements of each successful case.

\begin{tabular}{|c|c|c|}
\hline & Attribute & Items \\
\hline \multirow{3}{*}{ Alipay } & Security & $\begin{array}{l}\text { Free SMS alerts; digital certificates; SMS verification; shield; fingerprint verification; } \\
\text { security association with browser vendors \& antivirus vendors }\end{array}$ \\
\hline & Convenience & $\begin{array}{l}\text { Fee for water, electricity, LPG, phone, internet, cable TV, education, traffic fine, } \\
\text { and online game; ticket for train, film, and lottery; book for hospital and hotel; } \\
\text { channel of charity donation; channel of student loan project }\end{array}$ \\
\hline & Payment & Cooperation with 134 banks; quick payment; B2C payment; cross-border payment; large payment \\
\hline \multirow{2}{*}{ Yu'ebao } & Payment & Instant payment; quick transfer within 2 hours \\
\hline & Profitability & Profit by day \\
\hline \multirow{2}{*}{ Mobile wallet } & Quickness & Bar code scanning; QR code scanning; phone number payment; sound wave payment \\
\hline & Security & Advance compensation for stolen \\
\hline
\end{tabular}

company, Alibaba Co. and Tencent Co.; both have unique advantages in technology, mobile wallet's sound wave payment and TenPay wallet's QR code payment; both have large user bases, Alibaba's users and Tencent's users; and both are eager to occupy the leading position of the new mobile payment market. Since the advent of taxi app in 2013, mobile wallet and TenPay wallet, respectively, cooperate with two taxi apps Kuaidi and Didi. They totally took out billions of yuan to compensate the passengers and taxi drivers who use the taxi apps and pay by mobile wallet or TenPay wallet. The vigorous burning money activities are aimed at popularization of taxi apps superficially, but in fact, these are the disruptive marketing strategies of the two companies to cultivate their own mobile payment customer base. This "subsidizing" mode indeed turned to a good result. Mobile wallet survived in the battle. During that period, the payments completed by mobile wallet exceeded 2.78 billion times and RMB 900 billion in total. Since then, Alipay Co. becomes the biggest mobile payment company in worldwide. Thus, we propose a hypothesis:

H3.3. The "subsidizing" mode enables disruptive innovation to occupy the market quickly.

In such an intensely competitive market of 3rd-party online payment, to maintain current market shares, Alipay has made each effort to enhance current users' loyalty and satisfaction, launching multiple incentive products and services. For example, Alipay has launched credit score and its auxiliary services. Alipay objectively calculates users' credit scores according to credit history, behavior no., performing ability, identity, and interpersonal connections. Alipay has raised the concept of "make credit equal to wealth," feeding back corresponding services with users' credit scores to users, such as enhancing Ant Credit Pay limit, deposit-free borrowing, cash loan, installment consumption, and pay later.

To a certain extent, Sesame Credit Score meets users' social respect needs. The credit score is a recognition of the 


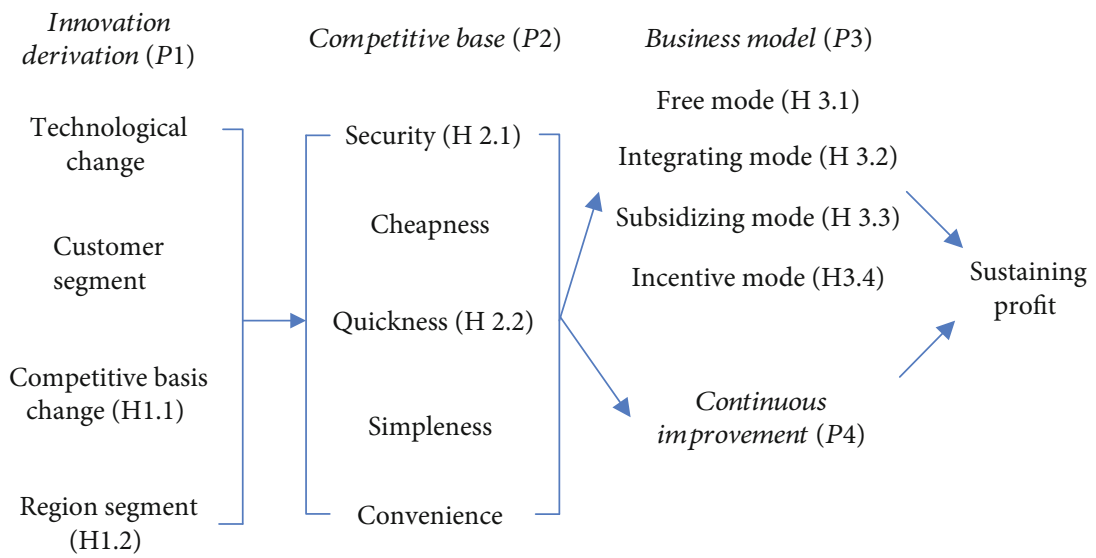

FIGURE 2: Characteristics of disruptive innovation of the 3rd-party online payment in China.

user's ability to perform credit. It not only enhances users' activity and users' stickiness but also reduces users' untrustworthy behavior. In another example, Alipay has also introduced features such as Yu'ebao. The profit of Yu'ebao is calculated at compound interest rate every day, and users can see the daily income of their Yu'ebao account. This is a psychological incentive that can significantly improve user satisfaction. Thus we, propose a hypothesis:

H3.4. The "incentive" mode enables disruptive innovation to maintain market share.

It should be noticed that the business model suited to disruptive innovation we proposed is different from the disruptive business model innovation on both the range of concept and the time innovation happens. Disruptive business model innovation generally refers to the entrant replaces the existing company's business model by a totally different model, through which it disrupts the incumbent [51]. The business model we proposed refers to the one improved or constructed to fit the disruptive innovation, no matter it is a disruptive technology innovation or a disruptive business model innovation. The business model can be either a disruptive one or a general one.

6.4. Continuous Improvement. The disruptive product usually underperforms on some product attributes at the beginning. To success in the end, it needs to improve its product attributes until they meet the "good enough" point. Alipay, Yu'ebao, and mobile wallet all implement the subsequent continuous improvement after advent. The details are shown in Table 5.

\section{Conclusion}

7.1. Findings. The point we focus on is the common characteristics in successful disruptive innovations of the 3rdparty online payment in China. The existing researches mainly focused on the traditional industries in the context of developed countries [8,9] or focused on the theory descriptive stage $[6,22]$. However, the situation of 3rdparty online payment in Chinese context is unprecedented and complicated, but inevitable to confront if someone wants to contend for this attractive market. Therefore, we conclude some propositions and hypotheses, shown in Figure 2, to enrich the disruptive innovation theory in the special and important context.

Our findings confirm that some propositions in disruptive innovation theory are also valid to the 3rd-party online payment in Chinese context and propose that some new points should be added to the propositions, such as innovation derivation (P1), product attributes (P2), business model (P3), and continuous improvement (P4). Context factors of the 3rd-party online payment in China facilitate new derivations for disruptive innovation. We suggest that competitive basis change (H1.1) is not only a feature but also a driver of disruptive innovation. Moreover, disruptive innovation may also come from region segment (H1.2) causing by regulations. Under the derivations and context factors, the product attributes that customers' appreciations are no longer limited to cheapness, simplicity, and convenience. They also highlight security (H2.1) and quickness (H2.2).

In addition, we suggest that subsequent stages of disruptive innovation are also important. The suitable business model (P3) should be constructed. No matter the business model by itself is disruptive or not, it must fit the disruptive innovation. At the same time, continuous improvement (P4) should be done in order to gain the sustaining profit.

7.2. Implications. Our findings do not only confirm and enrich the disruptive innovation theory, but also give some suggestions for the emerging companies especially 3rdparty online payment when implementing disruptive innovation in China in the future.

First, companies could diversify through disruptive innovation. The single innovation diffusion curve is presented as an "S." It will always go into the low-growth stage unless it is disrupted or replaced. Gopalakrishnan and Bierly stated that sustaining innovation tends to strengthen company's competitiveness [52], while disruptive innovation tends to diversify by exploring new markets and changing the focus of the industry competition. Therefore, for the companies who are in the low-growth stage of sustaining innovation, it is not a bad choice to conduct the disruptive innovation. It can not only diversify the business scope so as to continue 
the rapid-growth but also promote the mutual benefit among each business.

Second, a business model should suit to disruptive innovation. The profitability of the integration is far more important than that of innovation itself. From the cases of Alipay Co., the profit of its disruptive products is low, even negative, in quite a long time. However, Alipay Co. realizes overall profit and continuous user number increase by constructing suitable business models. It enlightens companies to have a long-term and overall sight. They should learn to pay more attention to construct suitable business models to realize overall profit as well as attaching importance to the disruptive innovation itself.

Third, the emerging technology such as data mining makes it possible to find out innovation opportunity in the information burst. The key reason why Alipay Co. is able to seize the "window of opportunity" of innovation every time refers to its large database and its ability of data mining. Ma Yun once stated that the development of Ali would go through three stages: guarantee-platform-data. No matter the 3rd-party payment or other industries, it would fail in the competition if it is unclear with the change of external environment. Therefore, it is necessary to dig into the knowledge behind the burst data, to identify the trend of disruptive technology and the change of market demand structure, and to adjust the business model and strategic sensitively in an effort to maintain competitive advantage.

\section{Limitations}

Our study focuses on the field of 3rd-party online payment. Although the industry of third-party online payment becomes mature, there are few studies on disruptive innovation of digital products or services. It still has its specificities. The findings concluded from 3rd-party online payment looks forward to be verified in general industry in the future research. In addition, the propositions and hypotheses are built on 6 cases of Alipay Co. and PayPal Co. Although they are outstanding enough to be representative, future studies could include more cases to find more universal conclusions.

\section{Data Availability}

No data were used to support this study.

\section{Conflicts of Interest}

The authors declare that they have no conflicts of interest.

\section{Acknowledgments}

This research was supported by the National Natural Science Foundation of China (Grant no. 71573064) and Key Consulting Program of Chinese Academy of Engineering (Grant no. GCZY20190001).

\section{References}

[1] Analysys, "EnfoDesk analysis: shares of the 3rd-party payment platform in the online trading in the 1rd quarter of 2020," 2020, 2020, https://www.analysys.cn/article/detail/20019827.

[2] C. M. Christensen, The Innovator's Dilemma: When New Technologies Cause Great Firms to Fail, Harvard Business School Press, Boston, 1997.

[3] C. M. Christensen and M. E. Raynor, The Innovator's Solution: Creating and Sustaining Successful Growth, Harvard Business School Press, Boston, 2003.

[4] C. M. Christensen, R. M. Mcdonald, E. J. Altman, and J. Palmer, "Disruptive innovation: intellectual history and future paths," Academy of Management Proceedings, vol. 2017, no. 1, article 14218, 2017.

[5] S. Corsi and A. D. Minin, "Disruptive innovation ... in reverse: adding a geographical dimension to disruptive innovation theory," Creativity and Innovation Management, vol. 23, no. 1, pp. 76-90, 2014.

[6] V. Govindarajan and P. K. Kopalle, "The usefulness of measuring disruptiveness of innovations ex post in making ex ante predictions," Journal of Product Innovation Management, vol. 23 , no. 1 , pp. 12-18, 2006.

[7] G. J. Tellis, "Disruptive technology or visionary leadership?," Journal of Product Innovation Management, vol. 23, no. 1, pp. 34-38, 2006.

[8] C. M. Christensen, S. D. Anthony, and E. A. Roth, Seeing What's Next, Harvard Business School Press, Boston, 2004.

[9] S. Huesig, K. Timar, and C. Doblinger, "The influence of regulation and disruptive potential on incumbents' submarket entry decision and success in the context of a network industry," Journal of Product Innovation Management, vol. 31, no. 5, pp. 1039-1056, 2014.

[10] C. M. Christensen, M. Raynor, and R. Mcdonald, "What Is Disruptive Innovation?," Harvard Business Review, vol. 93, no. 12, pp. 44-53, 2015.

[11] L. J. III Bourgeois and K. M. Eisenhardt, "Strategic decision processes in high velocity environments: four cases in the microcomputer industry," Management Science, vol. 34, no. 7, pp. 816-835, 1988.

[12] R. Hoover, "From gutenberg to zuckerberg: disruptive innovation in the age of the internet," Library Journal, vol. 138, no. 20, p. 115, 2013.

[13] D. G. Sirmon, M. A. Hitt, and R. D. Ireland, "Managing firm resources in dynamic environments to create value: looking inside the black box," Academy of Management Review, vol. 32, no. 1, pp. 273-292, 2007.

[14] E. P. Morais, J. A. Pires, and R. M. Goncalves, "E-business maturity: constraints associated with their evolution," Journal of Organizational Computing and Electronic Commerce, vol. 22, no. 3, pp. 280-300, 2012.

[15] J. K. Ryan, D. Sun, and X. Y. Zhao, "Competition and coordination in online marketplaces," Production and Operations Management, vol. 21, no. 6, pp. 997-1014, 2012.

[16] R. Varadarajan, R. G. Srinivasan, M. S. Vadakkepatt et al., "Interactive technologies and retailing strategy: a review, conceptual framework and future research directions," Journal of Interactive Marketing, vol. 24, no. 2, pp. 96-110, 2010.

[17] G. Lao and S. Jiang, "Risk analysis of third-party online payment based on PEST model," in International Conference on 
Management and Service Science, MASS 2009, IEEE Computer Society, pp. 1-5, Washington, D.C., 2009.

[18] People's Bank Of China, "Non-financial payment services management method," 2010, January 2014, http://www.gov .cn/flfg/2010-06/21/content_1632796.htm.

[19] R. Henderson, “The innovator's dilemma as a problem of organizational competence," Journal of Product Innovation Management, vol. 23, no. 1, pp. 5-11, 2006.

[20] Y. Chen, D. Luo, and W. Li, "Political connections, entry barriers, and firm performance," Chinese Management Studie, vol. 8, no. 3, pp. 473-486, 2014.

[21] S. Salomo, H. G. Gemunden, and R. Leifer, "Research on corporate radical innovation systems-a dynamic capabilities perspective: an introduction," Journal of Engineering and Technology Management, vol. 24, no. 1-2, pp. 1-10, 2007.

[22] C. M. Christensen, "The ongoing process of building a theory of disruption," Journal of Product Innovation Management, vol. 23, no. 1, pp. 39-55, 2006.

[23] S. R. Habtay, "A firm-level analysis on the relative difference between technology-driven and market-driven disruptive business model innovations," Creativity and Innovation Management, vol. 21, no. 3, pp. 290-303, 2012.

[24] N. Sultan, "Knowledge management in the age of cloud computing and Web 2.0: experiencing the power of disruptive innovations," International Journal of Information Management, vol. 33, no. 1, pp. 160-165, 2013.

[25] S. T. Walsh, "Roadmapping a disruptive technology: a case study: the emerging microsystems and top-down nanosystems industry," Technological Forecasting and Social Change, vol. 71, no. 1-2, pp. 161-185, 2004.

[26] P. R. Lawrence and J. W. Lorsch, "Differentiation and integration in complex organizations," Administrative Science Quarterly, vol. 12, no. 1, pp. 1-47, 1967.

[27] J. G. March, "Parochialism in the evolution of a research community: the case of organization studies," Management and Organization Review, vol. 1, no. 1, pp. 5-22, 2005.

[28] A. S. Tsui, "From homogenization to pluralism: international management research in the academy and beyond," Academy of Management Journal, vol. 50, no. 6, pp. 1353-1364, 2007.

[29] D. A. Whetten, "An examination of the interface between context and theory applied to the study of chinese organizations," Management and Organization Review, vol. 5, no. 1, pp. 29$56,2009$.

[30] P. B. Smith, "Chinese management theories: indigenous insights or lessons for the wider world," in The Handbook of Chinese Organizational Behavior: Integrating Theory, Research and Practice, X. Huang and M. H. Bond, Eds., pp. 502-510, Edward Elgar Pub, Northampton, Massachusetts, 2012.

[31] J. M. Utterback and W. J. Abernathy, "A dynamic model of process and product innovation," Omega, vol. 3, no. 6, pp. 639-656, 1975.

[32] J. M. Utterback, Mastering the Dynamics of Innovation, Harvard Business School Press, Boston, 1994.

[33] K. M. Eisenhardt, "Better stories and better constructs: the case for rigor and comparative logic," Academy of Management Review, vol. 16, no. 3, pp. 620-627, 1991.

[34] M. Ketokivi and S. Mantere, "Two strategies for inductive reasoning in organizational research," Academy of Management Review, vol. 35, no. 2, pp. 315-333, 2010.

[35] S. E. Toulmin, The Uses of Argument (Updated Ed.), Cambridge University Press, Cambridge, 2003.
[36] S. D. N. Cook and J. S. Brown, "Bridging epistemologies: the generative dance between organizational knowledge and organizational knowing," Organization Science, vol. 10, no. 4, pp. 381-400, 1999.

[37] R. K. Yin, Case Study Research: Design and Methods, Sage, Beverly Hills, 1984.

[38] C. Zhou, "The use of secondary data in management research," in Empirical Methods in Organization and Management Research, 2nd Edition, X. Chen, S. Xu, and J. Fan, Eds., Peking University Press, Beijing, 2012.

[39] R. Adner, "When are technologies disruptive? A demandbased view of the emergence of competition," Strategic Management Journal, vol. 23, no. 8, pp. 667-688, 2002.

[40] K. M. Eisenhardt and L. J. III Bourgeois, "Politics of strategic decision making in high-velocity environments: toward a midrange theory," Academy of Management Journal, vol. 31, no. 4, pp. 737-770, 1988.

[41] M. T. Hannan and J. Freeman, "The population ecology of organizations," American Journal of Sociology, vol. 82, no. 5, pp. 929-964, 1977.

[42] H. R. Greve, "Marketing niche entry decisions: competition, learning, and strategy in Tokyo banking, 1894-1936," Academy of Management Journal, vol. 43, no. 5, pp. 816-836, 2000.

[43] Y. Zhou and Q. Zhang, "Disruptive online service innovation in the presence of competition among disruptors: the case of 3rd-party online payment," International Journal of Services Technology and Management, vol. 25, no. 3/4, pp. 384-403, 2019.

[44] W. Zhang, T. Daim, and Q. Zhang, "Understanding the disruptive business model innovation of E-business microcredit: a comparative case study in China," Technology Analysis and Strategic Management, vol. 30, no. 2, pp. 1-13, 2018.

[45] J. L. Bower and C. M. Christensen, "Disruptive technologies: catching the wave," Harvard Business Review, vol. 73, no. 1, pp. 43-53, 1995.

[46] T. Kyoseva, V. Poulkov, M. Mihaylov, and A. Mihovska, "Disruptive innovations as a driving force for the change of wireless telecommunication infrastructures," Wireless Personal Communications, vol. 78, no. 3, pp. 1683-1697, 2014.

[47] K. Ripley, "The role of business ecosystems in the building of disruptive innovations," in Academy of Management Annual Meeting Proceedings, p. 15200, Atlanta, Ga, 2017.

[48] SouhuNet, "Just now, Yu'ebao announced that the number of its users exceeded 600 million, enable customers to earn 170 billion," 2019, January 2019, https://www.sohu.com/a/ 287596237_100120495.

[49] J. Sun, R. Tan, and P. Jiang, "Model for roadmapping disruptive innovation based on technology evolution theory," Journal of Mechanical Engineering, vol. 48, no. 11, pp. 11-20, 2012.

[50] H. Chen, H. Liu, and H. Cheung, "Radical innovation, market forces, political and business relationships," Chinese Management Studies, vol. 8, no. 2, pp. 218-240, 2014.

[51] G. Simmons, M. Palmer, and Y. Truong, "Inscribing value on business model innovations: insights from industrial projects commercializing disruptive digital innovations," Industrial Marketing Management, vol. 42, no. 5, pp. 744-754, 2013.

[52] S. Gopalakrishnan and P. Bierly, "Analyzing innovation adoption using a knowledge-based approach," Journal of Engineering and Technology Management, vol. 18, no. 2, pp. 107-130, 2001. 